\title{
ANALISIS PENGARUH FAKTOR-FAKTOR KOMPETENSI (LATAR BELAKANG PENDIDIKAN, PENGALAMAN, KOMPETENSI TEKNIK) TERHADAP KINERJA AUDITOR (STUDI KASUS PADA INSPEKTORAT KABUPATEN LAMONGAN)
}

\author{
*( Muhammad Chusnul Khitam \\ Prodi Manajemen, Fakultas Ekonomi, Universitas Islam Lamongan \\ $\mathrm{Jl}$. Veteran No.53A Lamongan \\ Telp. ( 0322 ) 324706, Faks. ( 0322 ) 324706 \\ Email :jpim.unisla@gmail.com
}

\begin{abstract}
ABSTRAK
Penelitian ini merupakan jenis penelitian kuantitatif pada Inspektorat Kab. Lamongan dengan judul "analis pengaruh faktor-faktor kompetensi (latar belakang pendidikan, pengalaman, kompetensi teknik) terhadap kinerja auditor (studi kasus pada inspektorat kabupaten lamongan)". Menganalisis adanya pengaruh secara parsial, simultan dan dominan variabel Latar belakang pendidikan, pengalaman, dan kompetensi teknik terhadap kinerja auditor. Tahap-tahap analisis yang digunakan oleh penulis dalam penelitian adalah : (1) uji validitas (2) uji reliabilitas (3) regresi berganda (4) korelasi sederhana (5) koefisien determinasi (6) uji t (7) uji F. Hasil penelitian pada Inspektorat Kab. Lamongan menunjukkan (1) ada pengaruh secara Simultan dan parsial terhadap kinerja Auditor pada Inspektorat Kab. Lamongan (2) Pengalaman mempunyai pengaruh paling dominan. Kesimpulan dari penelitian ini adalah ketiga variable bebas dapat meningkatkan kinerja Auditor pada Inspektorat Kab. Lamongan.
\end{abstract}

Kata kunci: Latar belakang Pendidikan, Pengalaman, Kompetensi Teknik dan Kinerja Auditor

\section{PENDAHULUAN}

Tuntutan

pelaksanaan

akuntabilitas sektor public terhadap good governance di semakin meningkat. Tuntutan ini memang wajar, karena beberapa penelitian menunjukkan bahwa terjadinya krisis ekonomi di Indonesia ternyata disebabkan oleh buruknya pengelolaan pemerintahan (bad governance) dan buruknya birokrasi (Efendy, 2010). Akuntabilitas sektor publik berhubungan dengan praktik transparansi dan pemberian informasi kepada publik dalam rangka pemenuhan hak publik.

Terdapat tiga aspek yang mendukung terciptanya kepemerintahan yang baik (good govermance). yaitu pengawasan, pengendalian dan pemeriksaan. Pengawasan merupakankegiatan yang dilakukan oleh pihak di luar eksekutif. Yaitu masyarakat dan Dewan Perwakilan Rakyat Daerah (DPRD) (Efendy, 2010). Pengendalian 
(control) adalah mekanisme yang dilakukan oleh eksekutif menjamin bahwa system dan kebijakan manajemen dilaksanakan dengan baik sehinggah tujuan morganisasi bisa tercapai. Sedangkan pemeriksaan (audit) merupakan kegiatan yang dilakukan oleh pihak yang memiliki indepedensi dan memiliki kompetensi professional untuk memeriksa apakah hasil kinerja pemerintah telah sesuai dengan standar yang ditetapkan.

Secara garis besar di Indonesia yang melaksanakan fungsi pemeriksaan dipisahakan menjadi dua bagian yaitu auditor eksternal dan internal. Auditor eksternal pemerintah diimplementasikan oleh Badan Pemeriksan Keuangan (BPK) yang dibentuk sebagai perwujudan Pasal 23E UUD 1945 dimana BPK adalah lembaga tinggi negara yang melakukan audit atas Pertanggungjawaban Keuangan President Republik Indonesia dan Aparat dibawahnya dan melaporkan kepada Dewan Perwakilan Rakyat (DPR). Sedangkan Auditor internal pemerintah diimplementasikan oleh Badan Pengawasan Daerah (BAWASDA) yang saat ini berubah nama menjadi INSPEKTORAT dan badan pengawas internal di setiap departemen yaitu Inspektorat Jendral (IRJEN). Salah satu unit yang melakukan audit pemeriksaan terhadap pemerintah daerah adalah Inspektorat Daerah (Propinsi/kabupaten/kota).

Inspektorat Kabupaten Lamongan dibentuk berdasarkan peraturan daerah Kabupaten Lamongan No 04 Tahun
2008 tentang Organisasi dan Tata Kerja Lembaga Teknis Daerah Kabupaten Lamongan yang di pimpin oleh seorang Inspektur berkedudukan dibawah dan bertanggungjawab kepada Kepala Daerahdan secara teknis administratif mendapat pembinaan dan Sekretaris Daerah. Sebagaimana peratuiran Bupati Lamongan No. 04 Tahun 2008 tentang Kedudukan, Tugas dan Fungsi Inspektorat Kabupaten Lamongan pada pasal 3 mempunyai pokok yaitu "Melaksanakan pengawasan terhadap pelaksanaan urusan pemerintah didaerah, pelaksanaan pembinaan atas penyelenggaraan Pemerintah dan pelaksanaan urusan Pemerintahan Desa".

Pengawasan yang dilakukan auditor pemerintah memiliki peran yang sangat penting dalam menciptakan efisiensi nasional, sehingga auditor pemerintah harus menjaga dan meningkatkan profesionalisme dalam melaksanakan tugasnya Untuk membuktikan keahlian atau profesionalisme seorang auditor harus memiliki pengalaman dalam pratek audit, karena auditor yang tidak berpengalaman dalam melakukan kesalahan yang lebih besar dibandingkan auditor yang berpengalaman. Selain itu auditor yang berpengalaman akan dapat dengan mudah melakukan deteksi kesalahan, memahami kesalahan dan mecari penyebab munculnya kesalahan. Kualitas audit menurut De Angelo yang dikutip Indriantoro (1998) adalah sebagai probabilitas bahwa auditor akan menemukan dan 
melaporkan pelanggaran pada sistem akuntansi klien. Probabilitas untuk menemukan pelanggaran sangat tergantung pada Auditor itu sendiri, dengan kata lain latar belakang pendidikan, Pengalaman dan Kompetensi teknik auditor dapat mempengaruhi kualitas hasil audit.

Berdasarkan Peraturan Menteri Negara Pendayagunaan Aparatur Negara Nomor :PER/05/M.PAN/03/2008 tanggal 31 Maret 2008 tentang Standar Audit Aparat Pengawasan Intern Pemerintah disebutkan bahwa latar pendidikan Auditor APIP, paling tidak mempunyai tingkat pendidikan formal minimal Strata satu (S-1) atau yang setara. Hal itu agar tercipta kinerja audit, mengidentifikasi kebutuhan profesional auditor dan untuk mengembangkan teknik dan metodologi audit agar sesuai dengan situasi dan kondisi yang dihadapi unit yang dilayani APIP.

Berdasarkan Surat BPKP Nomor: S-205/K/JF/2014 tentang Persetujuan Pengangkatan ke dalam Jabatan Fungsional Auditor pada Inspektorat Kabupaten Lamongan. Dari perihal di atas peneliti tertarik melakukan penelitian di Inspektorat Kabupaten Lamongan tentang pemindahan Pejabat Strukutural menjadi Pejabat Fungsional.

Rumusan masalah pada penelitian ini adalah (1) Apakah Faktor-faktor Kompetensi (Latar belakang Pendidikan, Pengalaman dan Kompetensi Teknik) berpengaruh secara Simultan terhadap kinerja auditor pada Inspektorat Kabupaten
Lamongan? (2) Apakah Faktor-faktor Kompetensi (Latar belakang Pendidikan, Pengalaman dan Kompetensi Teknik) berpengaruh secara Parsial terhadap kinerja auditor pada Inspektorat Kabupaten Lamongan ? (3) Dari ketiga Faktor tersebut (Latar belakang Pendidikan, Pengalaman dan Kompetensi Teknik) faktor manakah yang berpengaruh paling dominan terhadap kinerja auditor pada Inspektorat Kabupaten Lamongan?

Adapun tujuan dari penelitian ini adalah (1) Untuk mengetahui Faktorfaktor Kompetensi (Latar belakang Pendidikan, Pengalaman dan Kompetensi Teknik) berpengaruh secara Simultan terhadap kinerja auditor pada Inspektorat Kabupaten Lamongan.? (2) Untuk mengetahui Faktor-faktor Kompetensi (Latar belakang Pendidikan, Pengalaman dan Kompetensi Teknik) berpengaruh secara Parsial terhadap kinerja auditor pada Inspektorat Kabupaten Lamongan.? (3) untuk mengetahui dari ketiga faktor tersebut (Latar belakang Pendidikan, Pengalaman dan Kompetensi Teknik) Faktor manakah yang berpengaruh paling dominan terhadap kinerja auditor pada Inspektorat Kabupaten Lamongan.

\section{LANDASAN TEORI}

Manusia adalah makhluk yang diciptakan dengan memiliki sifat-sifat yang berbeda dengan makhluk lain yang hidup di dunia ini. Manusia adalah makhluk yang sempurna karena memiliki sifat-sifat fisik maupun psikis yang dapat 
menyesuaikan dengan kebutuhan hidupnya di dunia ini. Kesemua sifat dasar yang dimiliki manusia akan tumbuh dan berkembang secara alamiah bila manusia mengalami proses perkembangan fisik dan psikisnya secara normal melalui proses yang secara sadar diarahkan kepada tercapainya berbagai sifat baik tersebut, melalui suatu proses yang disebut pendidikan.

Di dalam nuansa kependidikan, manusia adalah sasaran pendidikan sekaligus subjek pendidikan. Pendidikan membantu manusia dalam menumbuhkan dan mengembangkan potensi-potensi kemanusiaan yang ada dalam dirinya. Potensi kemanusiaan merupakan benih untuk mengembangkan seseorang menjadi manusia seutuhnya. Pemahaman dari pendidik terhadap potensi-potensi dan sifat hakikat manusia sangat penting agar pendidikan mencapai tujuan yang diharapkan yaitu memanusiakan manusia. Pendidikan harus diarahkan kepada pencapaian tujuan itu melalui perumusan dan penerapan konsep pendidikan. Masalah utama dalam pendidikan adalah bagaimana mengembangkan semua kemampuan dasar yang dimiliki manusia sejak lahir itu akan dapat berkembang, sehingga manusia dapat berperan baik sebagai individu maupun sebagai makhluk sosial dengan tetap berada di dalam lingkup hakikat kemanusiannya. Dalam tugas Mata Kuliah Kajian Teori Pendidikan dan Pembelajaran ini, penulis akan memaparkan beberapa konsep teori pendidikan dan pembelajaran dari beberapa pakar pendidikan.

\section{METODE PENELITIAN}

Jenis penelitian yang digunakan oleh penulis adalah penelitian kuantitatif. Menurut Sugiyono (2012:7) metode penelitian kuantitatif dapat diartikan sebagai metode penelitian yang berlandaskan pada filsafat positivisme, digunakan untuk meneliti pada populasi atau sampel tertentu. Metode ini disebut metode kuantitatif karena data penelitian berupa angka-angka dan analisis menggunakan statistik.

Validitas adalah suatu ukuran yang menunjukkan tingkat kevalidan atau kesahihan suatu instrumen (Riduwan dan Sunarto,2013:348). Uji validitas ini secara manual di hitung dengan cara mengkorelasikan setiap skor item dengan total skor item variabel kemudian hasilnya dibandingkan $r$ product moment. Untuk mencari $\mathrm{r}$ hitung atau koefisien korelasi product moment digunakan rumus :

$$
\mathrm{r}=\frac{n \sum x y-\left(\sum x\right)\left(\sum x\right)}{\sqrt{\left\{\left(n \sum x-\left(\sum x\right)\right\}-\left\{n \sum y-\left(\sum y\right)\right\}\right.}}
$$

Keterangan :

$\mathrm{r}=$ Koefisien Korelasi

$\mathrm{x}=$ Variabel Independent

$\mathrm{y}=$ Variabel Dependent

$\mathrm{n}=$ Jumlah Responden

Reliabilitas menunjuk pada suatu pengertian bahwa sesuatu instrumen dapat dipercaya untuk digunakan sebagai alat pengumpul data karena instrumen tersebut sudah dianggap baik. (Riduwan dan 
Sunarto,2013:348). Adapun cara yang digunakan untuk menguji reliabilitas kuesioner dalam penelitian ini adalah menggunakan rumus koefisien Alpha Cronbach, yaitu:

$$
r_{u}=\left(\frac{k}{k-1}\right)\left(\frac{1-\sum_{a e} 2}{a_{1^{2}}}\right)
$$

Keterangan :

$\mathrm{r}_{\mathrm{u}} \quad=$ Reliabilitas Konsumen

$\mathrm{k}=$ Banyaknya Butir Pertanyaan

$\sum_{a e} 2=$ Jumlah Varian Butir

$\mathrm{A}_{1}{ }^{2}=$ Varian Total

Analisis regresi berganda ialah suatu alat analisis peramalan nilai pengaruh dua variabel bebas atau lebih terhadap variabel terikat untuk membuktikan ada atau tidaknya hubungan fungsi atau hubungan kausal antara dua variabel bebas atau lebih dengan satu variabel terikat (Riduwan dan Sunarto, 2013:108). Rumus regresi ganda adalah sebagai berikut:

$\mathrm{Y}=\mathrm{a}+\mathrm{b}_{1} \mathrm{x}_{1}+\mathrm{b}_{2} \mathrm{x}_{2}+\mathrm{b}_{3} \mathrm{x}_{3}$

a $=$ intersep /konstanta

$\mathrm{b}_{1}, \mathrm{~b}_{2}, \mathrm{~b}_{3}=$ koefisien regresi

$\mathrm{x}_{1}=$ variabel Latar Belakang

Pendidikan

$\mathrm{x}_{2} \quad=$ variabel Pengalaman

$\mathrm{x}_{3} \quad=$ variabel Kompetensi Teknik

$\mathrm{Y} \quad=$ variabel kinerja Auditor

Korelasi sederhana (korelasi Product moment) digunakan untuk mengetahui hubungan antar variabel jika ada data yang digunakan memiliki skala interval atau rasio (sugiyono,2012:224) $r$ xy merupakan koefisien korelasi yang nilainya akan senantiasa berkisar antara -1 sampai dengan 1. Bila koefisien korelasi tersebut mendekati 0 berarti korelasi tersebut semakin melemah (sulianto, 2011:16).

$$
\begin{array}{ll}
\mathrm{r}_{\mathrm{xy}}=\frac{n \sum x y-\left(\sum x\right)\left(\sum y\right)}{\left.\sqrt{\left\{n \sum x^{2}\right.}-\left(\sum x\right)^{2}\right\}-\left\{n \sum y^{2}-\left(\sum y\right)^{2}\right\}} \\
\text { keterangan: } \\
\mathrm{r} \quad: \text { koefisien korelasi } \\
\mathrm{X}_{1} \quad \text { : Latar Belakang Pendidikan } \\
\mathrm{X}_{2} \quad \text { : Pengalaman } \\
\mathrm{X}_{3} \quad: \text { Kompetensi teknik } \\
\mathrm{Y} \quad: \text { Kinerja Auditor }
\end{array}
$$

Koefisien determinasi merupakan ukuran-ukuran untuk mengetahui kesesuaian atau ketepatan antara nilai dugaan atau garis regresi dengan data sampel. Untuk mengetahui seberapa persen besarnya hubungan antara variabel $\mathrm{X}$ dengan variabel $\mathrm{Y}$ maka menggunakan analisis Koefisien Determinasi yang diperoleh dengan mengkuadratkan koefisien korelasinya (Riduwan dan Sunarto, 2013:81) atau dapat dirumuskan sebagai berikut :

$$
K d=r^{2} \times 100 \%
$$

Keterangan :

$$
\begin{array}{ll}
K d & =\text { Koefisien Determinasi } \\
\mathrm{r} & =\text { Koefisien Korelasi }
\end{array}
$$

\section{Uji t}

Pengujian ini bertujuan untuk menguji apakah variabel bebas (Latar belakang pendidikan, Pengalaman, Kompetensi Teknik) terhadap varibel terikat (kinerja Auditor) berpengaruh secara parsial atau pervariabel. Untuk mengetahui tingkat signifikansi dari koefisien korelasi, maka menggunakan statistik Uji t (Sugiyono, 2013:259) dengan rumus:

$t_{\text {hitung }}=\frac{r \sqrt{n-2}}{\sqrt{1-r^{2}}}$

Keterangan : 
$\mathrm{t}=$ hasil uji tingkat signifikansi

$r \quad=$ koefisien korelasi

$\mathrm{n}=$ jumlah data

Perumusan Hipotesis :

$\mathrm{H}_{0}: \mathrm{b}_{1}=\mathrm{b}_{2}=\mathrm{b}_{3}=0$, tidak ada pengaruh variabel $\mathrm{X}$ dengan variabel Y.

$\mathrm{H}_{0}: \mathrm{b}_{1} \neq \mathrm{b}_{2} \neq \mathrm{b}_{3} \neq 0$, minimal ada satu pengaruh dari implementasi variabel $\mathrm{X}$ terhadap variabel $\mathrm{Y}$.

\section{Uji F}

Uji $F$ bertujuan untuk menguji pengaruh variabel secara simultan atau bersama-sama (Sugiyono, 2013:266) Uji F dapat dihitung dengan menggunakan rumus :

$F=\frac{R^{2} / k}{\left(1-R^{2}\right) /(n-k-1)}$

Keterangan :

$\mathrm{F}=\mathrm{F}$ hitung yang selanjutnya dibandingkan dengan $\mathrm{F}$ tabel

$\mathrm{R}^{2}=$ Koefisien Korelasi yang telah ditentukan

$\mathrm{K}=$ Jumlah variabel independen

$\mathrm{n}=$ Jumlah anggota sampel

Rumusan Hipotesis :

$\mathrm{H}_{0}=$ tidak ada pengaruh antara variabel $\mathrm{X}$ dengan variabel $\mathrm{Y}$

$\mathrm{H}_{\mathrm{a}}=$ ada pengaruh antara variabel $\mathrm{X}$ dengan variabel $\mathrm{Y}$

Daerah kritis $\mathrm{H}_{\mathrm{o}}$ melalui kurva distribusi $F$

\section{HASIL PENELITIAN PEMBAHASAN} DAN

Berikut ini adalah data hasil uji validitas pada variable yang digunakan dengan bentuk indicator sebagai berikut :
Tabel 1.

Rekapitulasi Hasil Uji Validitas

\begin{tabular}{|c|c|c|c|c|c|}
\hline $\begin{array}{l}\mathrm{N} \\
\mathrm{O}\end{array}$ & $\begin{array}{l}\text { Variabel } \\
\text { Indikator }\end{array}$ & $\begin{array}{c}\text { No } \\
\text { pertan } \\
\text { yaan }\end{array}$ & $\begin{array}{c}\mathrm{r} \\
\text { hitung }\end{array}$ & $\begin{array}{c}\mathrm{r} \\
\text { tabel }\end{array}$ & $\begin{array}{c}\text { Ketera } \\
\text { ngan }\end{array}$ \\
\hline \multirow[t]{2}{*}{1} & \multirow{2}{*}{$\begin{array}{l}\text { Latar } \\
\text { belakang } \\
\text { Pendidik } \\
\text { an }\left(X_{1}\right)\end{array}$} & 1 & 0,655 & 0,468 & Valid \\
\hline & & 2 & 1 & 0,468 & Valid \\
\hline \multirow[t]{2}{*}{2} & \multirow{2}{*}{$\begin{array}{l}\text { Pengala } \\
\operatorname{man}\left(X_{2}\right)\end{array}$} & 1 & 0,749 & 0,468 & Valid \\
\hline & & 2 & 1 & 0,468 & Valid \\
\hline \multirow[t]{3}{*}{3} & \multirow{3}{*}{$\begin{array}{l}\text { Kompete } \\
\text { nsi } \\
\text { Teknik } \\
\left(\mathrm{X}_{3}\right)\end{array}$} & 1 & 0,571 & 0,468 & Valid \\
\hline & & 2 & 0,632 & 0,468 & Valid \\
\hline & & 3 & 1 & 0,468 & Valid \\
\hline \multirow[t]{4}{*}{4} & \multirow{4}{*}{$\begin{array}{l}\text { Kinerja } \\
\text { Auditor } \\
(\mathrm{Y})\end{array}$} & 1 & 0,471 & 0,468 & Valid \\
\hline & & 2 & 0,535 & 0,468 & Valid \\
\hline & & 3 & 0,553 & 0,468 & Valid \\
\hline & & 4 & 1 & 0,468 & Valid \\
\hline
\end{tabular}

Sumber : Data diolah

Berdasarkan tabel 1 di atas semua indikator yang digunakan untuk mengukur variabel-variabel yang digunakan dalam penelitian ini mempunyai koefisien korelasi yang lebih besar dari $r$ tabel untuk $n=20$ yaitu 0,468 . Dengan demikian hal ini menunjukkan bahwa semua indikator sebagai pengukur dari masing-masing variabel tersebut adalah valid.

Tabel. 2

Rekapitulasi Hasil Uji Reliabilitas

\begin{tabular}{|c|l|c|c|c|}
\hline $\begin{array}{c}\mathrm{N} \\
\mathrm{o}\end{array}$ & Variabel & $\begin{array}{c}\text { Nilai } \\
\text { Alpha }\end{array}$ & $\begin{array}{c}\text { Standar } \\
\text { Reliabil } \\
\text { itas }\end{array}$ & $\begin{array}{c}\text { Keteran } \\
\text { gan }\end{array}$ \\
\hline 1 & $\begin{array}{l}\text { Latar } \\
\text { belakang } \\
\text { Pendidik } \\
\text { an }\end{array}$ & 0,898 & 0,60 & $\begin{array}{c}\text { Reliabe } \\
1\end{array}$ \\
\hline 2 & $\begin{array}{l}\text { Pengalam } \\
\text { an }\end{array}$ & 0,859 & 0,60 & $\begin{array}{c}\text { Reliabe } \\
1\end{array}$ \\
\hline 3 & $\begin{array}{l}\text { Kompete } \\
\text { nsi teknik }\end{array}$ & 0,839 & 0,60 & $\begin{array}{c}\text { Reliabe } \\
1\end{array}$ \\
\hline 4 & $\begin{array}{l}\text { Kinerja } \\
\text { auditor }\end{array}$ & 0,810 & 0,60 & $\begin{array}{c}\text { Reliabe } \\
1\end{array}$ \\
\hline
\end{tabular}

Sumber : Data diolah 
Dari tabel di atas, nilai alpha semua variabel bebasnya yaitu Latar belakang pendidikan, Pengalaman, Komptensi teknik dan Kinerja auditor lebih besar dari 0,60 dengan tingkat signifikasi $\alpha=5 \%$ sehingga dapat disimpulkan bahwa instrument dalam variabel bebas dan terikatnya reliabel.

Persamaan regresi dapat dijelaskan sebagai berikut:

$Y=1,786+0,467 \quad X_{1}+0,672 \quad X_{2}+$ $0,384 X_{3}$

a. $\mathrm{a}=1,786$ merupakan intersep (constanta) yang berarti bahwa apabila variabel bebas dalam penelitian ini (Latar belakang pendidikan, Pengalaman dan Kompetensi Teknik) pengaruhnya $=0$, maka hasil yang diperoleh dari kinerja auditor adalah 1,786

b. b1=0,467 artinya untuk variabel Latar belakang pendidikan koefisien regresi (b1) menunjukkan nilai 0,467 yang berarti apabila variabel Latar belakang pendidikan dinakaikan 1 satuan, maka kinerja auditor naik sebesar 0,467 dengan asumsi variabel lain dianggap nol. $\left(\mathrm{a}, \mathrm{X}_{2}, \mathrm{X}_{3}=0\right)$

c. $b 2=0,672$ artinya untuk variabel Pengalaman koefisien regresi (b2) menunjukkan nilai 0,672 yang berarti apabila variabel Pengalaman dinakaikan 1 satuan, maka kinerja auditor naik sebesar 0,672 dengan asumsi variabel lain dianggap nol. ( $a, X_{1}, X_{3}=0$ )

d. $b 3=0,384$ artinya untuk variabel Kompetensi Teknik koefisien regresi (b3) menunjukkan nilai 0,384 yang berarti apabila variabel Kompetensi teknik dinakaikan 1 satuan, maka kinerja auditor naik sebesar 0,384 dengan asumsi variabel lain dianggap nol. (a, $X_{1}$, $\mathrm{X}_{2}=0$ )

Dari koefisien variabel-variabel bebas di atas bernilai positif. Hal ini berarti mempunyai arah perubahan yang searah dengan variabel terikat. Di samping itu koefisien variabel Pengalaman dengan koefisien regresi sebesar 0,672 mempunyai nilai terbesar dibanding dengan koefisien regresi variable bebas yang lain(Latar belakang pendidikan, Kompetensi teknik). Dengan demikian dapat ditarik kesimpulan bahwa faktor yang paling dominan pengaruhnya terhadap kinerja auditor adalah faktor Pengalaman.

Korelasi sederhana (korelasi Product moment) digunakan untuk mengetahui hubungan antar variabel jika ada data yang digunakan memiliki skala interval atau rasio (sugiyono, 2012:224) $r_{x y}$ merupakan koefisien korelasi yang nilainya akan senantiasa berkisar antara -1 sampai dengan 1 . Bila koefisien korelasi tersebut mendekati 0 berarti korelasi tersebut semakin melemah (sulianto, 2011:16). Hasil uji korelasi sederhana dalam penelitian ini dapat dilihat pada hasil program SPSS dalam tabel berikut :

Berdasarkan hasil perhitungan regresi pada tabel di atas didapatkan suatu persamaan regresi sebagai berikut: 
Table 3.

Hasil uji korelasi sederhana

\begin{tabular}{|c|c|c|c|c|c|}
\hline \multicolumn{6}{|c|}{ Correlations } \\
\hline & & $\begin{array}{c}\text { Pend } \\
\text { idika } \\
\mathrm{n}\end{array}$ & $\begin{array}{l}\text { Penga } \\
\text { laman }\end{array}$ & $\begin{array}{l}\text { Kom_- } \\
\text { teknik }\end{array}$ & $\begin{array}{c}\text { Kiner } \\
\text { ja_Au } \\
\text { ditor }\end{array}$ \\
\hline \multirow{3}{*}{$\begin{array}{l}\text { Pend } \\
\text { idika } \\
n\end{array}$} & $\begin{array}{l}\text { Pearson } \\
\text { Correlation }\end{array}$ & 1 & $.589^{* * *}$ & $.569^{* * *}$ & $.736^{* * *}$ \\
\hline & $\begin{array}{l}\text { Sig. (2- } \\
\text { tailed) }\end{array}$ & & .006 & .009 & .000 \\
\hline & $\mathrm{N}$ & 20 & 20 & 20 & 20 \\
\hline \multirow{3}{*}{$\begin{array}{l}\text { Peng } \\
\text { alam } \\
\text { an }\end{array}$} & $\begin{array}{l}\text { Pearson } \\
\text { Correlation }\end{array}$ & .589 & 1 & $.679^{* *}$ & $.801^{* * *}$ \\
\hline & $\begin{array}{l}\text { Sig. (2- } \\
\text { tailed) }\end{array}$ & .006 & & .001 & .000 \\
\hline & $\mathrm{N}$ & 20 & 20 & 20 & 20 \\
\hline \multirow{3}{*}{$\begin{array}{l}\text { Kom } \\
\text { tek } \\
\text { nik }\end{array}$} & $\begin{array}{l}\text { Pearson } \\
\text { Correlation }\end{array}$ & .569 & $.679^{* *}$ & 1 & $.779^{* * *}$ \\
\hline & $\begin{array}{l}\text { Sig. (2- } \\
\text { tailed) }\end{array}$ & .009 & .001 & & .000 \\
\hline & $\mathrm{N}$ & 20 & 20 & 20 & 20 \\
\hline \multirow{3}{*}{$\begin{array}{l}\text { Kine } \\
\text { rja_- } \\
\text { Audi } \\
\text { tor }\end{array}$} & $\begin{array}{l}\text { Pearson } \\
\text { Correlation }\end{array}$ & .736 & $.801^{* *}$ & $.779^{* * *}$ & 1 \\
\hline & $\begin{array}{l}\text { Sig. (2- } \\
\text { tailed) }\end{array}$ & .000 & .000 & .000 & \\
\hline & $\mathrm{N}$ & 20 & 20 & 20 & 20 \\
\hline
\end{tabular}

Sumber : Pengolahan SPSS 17

Berdasarkan pengolahan data tabel di atas 5.19 korelasi di atas, maka dapat di uraikan sebagai berikut :

a. Nilai korelasi antara Latar Belakang Pendidikan $\left(r_{1}\right)$ dengan Kinerja Auditor (Y) pada Inspektorat Kab. Lamongan diperoleh 0,736 yang berarti ada hubungan/korelasi yang kuat dan signifikan, antara Latar belakang pendidikan $\left(r_{1}\right)$ dengan Kinerja Auditor (Y).

b. Nilai korelasi antara Pengalaman $\left(\mathrm{r}_{2}\right)$ dengan Kinerja Auditor ( $\mathrm{Y}$ ) pada Inspektorat Kab. Lamongan diperoleh 0,801 yang berarti ada hubungan/korelasi yang sangat kuat dan signifikan, antara Pengalaman $\left(\mathrm{r}_{2}\right)$ dengan Kinerja Auditor (Y). c. Nilai korelasi antara Kompetensi Teknik $\quad\left(\mathrm{r}_{3}\right)$ dengan Kinerja Auditor (Y) pada Inspektorat Kab. Lamongan diperoleh 0,779 yang berarti ada hubungan/korelasi yang kuat dan signifikan, antara Kompetensi teknik $\left(\mathrm{r}_{3}\right)$ dengan Kinerja Auditor (Y).

Korelasi ganda diperoleh 0,805 atau $80,5 \%$ maka arah dan derajat Latar belakang Pendidikan $\left(\mathrm{X}_{1}\right)$, Pengalaman $\left(\mathrm{X}_{2}\right)$ dan Kompetensi teknik $\left(\mathrm{X}_{3}\right)$ signifikan dan mempunyai hubungan sangat kuat terhadap kinerja (Y) dengan skala interval antara 0,800 - 1,000 ( Sugiyono, 2012 : 231 ). Berdasarkan tabel summary, nilai koefisien determinasi dapat diketahui dari nilai $\mathrm{R}$ Square yaitu sebesar 0,805. Dari nilai $\mathrm{R}^{2}$ tersebut dapat ditarik kesimpulan bahwa variabel Latar belakang pendidiakan, pengalaman, kompetensi teknik bersama-sama telah mampu menjelaskan atau menerangkan keragaman dari variabel terikat yaitu kinerja sebesar $80,5 \%$ sedangkan sisanya sebesar $19,5 \%$ dipengaruhi oleh variabel bebas lain yang tidak dimasukkan ke dalam model persamaan yaitu motivasi, Independsi dan komitmen.

Tabel 4.

Rekapitulasi Hasil Uji t

\begin{tabular}{|c|c|c|c|c|}
\hline $\begin{array}{c}\text { Variab } \\
\text { el }\end{array}$ & $\begin{array}{l}\text { Nilai } t \\
\text { hitung }\end{array}$ & $\begin{array}{l}\text { Nilai t } \\
\text { Table }\end{array}$ & $\begin{array}{l}\text { Kesim } \\
\text { pulan }\end{array}$ & Ket \\
\hline $\begin{array}{l}\text { Latar } \\
\text { belaka } \\
\text { ng } \\
\text { pendi } \\
\text { dikan } \\
\text { (X1) }\end{array}$ & 2,218 & 2.119 & $\begin{array}{c}\mathrm{H}_{1} \\
\text { Diteri } \\
\mathrm{ma}\end{array}$ & $\begin{array}{l}t_{\text {hitung }}> \\
t_{\text {tabel }}\end{array}$ \\
\hline
\end{tabular}




\begin{tabular}{|c|c|c|c|c|}
\hline $\begin{array}{c}\text { pengal } \\
\text { aman } \\
(\mathrm{X} 2)\end{array}$ & 2,418 & 2.119 & $\begin{array}{c}\mathrm{H}_{2} \\
\text { Diteri } \\
\text { ma }\end{array}$ & $\begin{array}{c}t_{\text {hitung }}> \\
t_{\text {tabel }}\end{array}$ \\
\hline $\begin{array}{c}\text { Kompt } \\
\text { ensi } \\
\text { teknik } \\
\text { (X3) }\end{array}$ & 2,153 & 2.119 & $\begin{array}{c}\mathrm{H}_{3} \\
\text { Diteri } \\
\text { ma }\end{array}$ & $\begin{array}{c}t_{\text {hitung }}> \\
t_{\text {tabel }}\end{array}$ \\
\hline
\end{tabular}

Sumber : Diolah

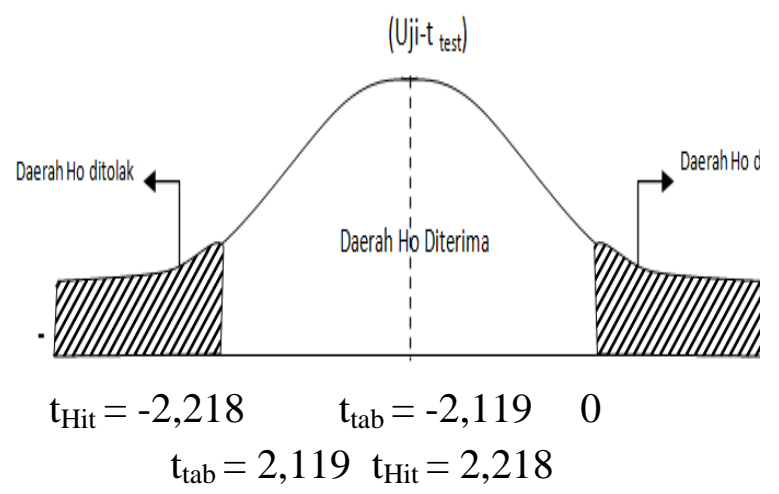

Gambar 1.

Daerah Penerimaan dan Penolakan

Latar belakang pendidikan (X1)

Dari hasil uji $\mathrm{t}$ diperoleh nilai $\mathrm{t}$ hitung $(2,218)$ lebih besar dari nilai $t$ tabel $(2,119)$ sehingga $t_{\text {hitung }}>t_{\text {tabel }}$ dengan tingkat signifikansi 0,05 maka H1diterima, yang artinya bahwa ada pengaruh yang signifikan antara Latar Belakang Pendidikan $\left(\mathrm{X}_{1}\right)$ dengan Kinerja Auditor (Y) pada Inspektorat Kab. Lamongan.

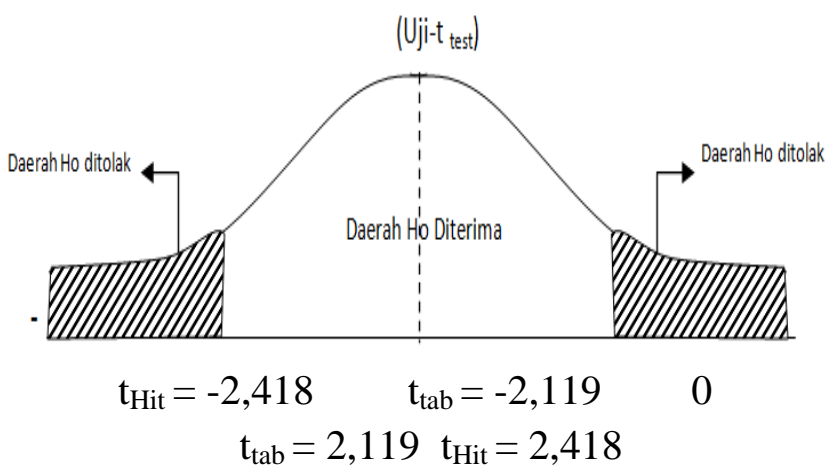

Gambar 2.

Daerah Penerimaan dan Penolakan Pengalaman (X2)
Dari hasil uji t diperoleh nilai t hitung $(2,418)$ lebih besar dari nilai t tabel $(2,119) \backslash$ sehingga $t_{\text {hitung }} \geq t_{\text {tabel }}$ dengan tingkat signifikansi 0,05 maka $\mathrm{H} 2$ diterima, yang artinya bahwa ada pengaruh yang signifikan antara Pengalaman $\left(\mathrm{X}_{2}\right)$ dengan Kinerja Auditor (Y) pada Inspektorat Kab. Lamongan.

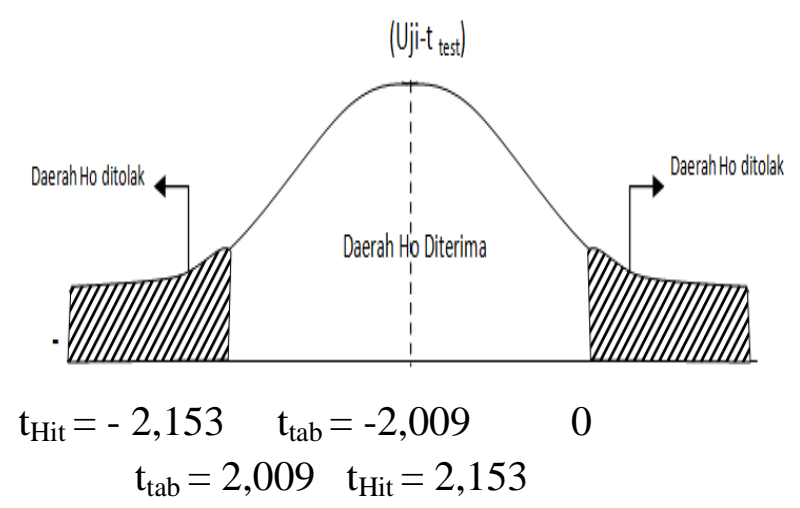

Gambar 3.

Daerah Penerimaan dan Penolakan Kompetensi teknik (X3)

Dari hasil uji $\mathrm{t}$ diperoleh nilai $\mathrm{t}$ hitung $(2,153)$ lebih besar dari nilai $t$ tabel $(2,119)$ sehingga $t_{\text {hitung }}>t_{\text {tabel }}$ dengan tingkat signifikansi 0,05 maka H3 diterima, yang artinya bahwa ada pengaruh yang signifikan antara Kompetensi teknik $\left(\mathrm{X}_{3}\right)$ dengan Kinerja Auditor (Y) pada Inspektorat Kab. Lamongan.

Hasil Uji F dapat dijelaskan dengan gambar berikut ini:

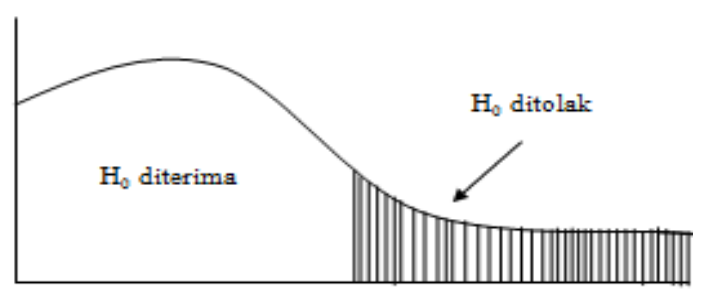

$\mathrm{F}_{\text {tabel }}=3,24 \mathrm{~F}_{\text {Hitung }}=22,022$ Gambar 4.

Daerah Penerimaan dan Penolakan 
Uji $\mathrm{F}$ digunakan untuk menguji signifikasi pengaruh secara simultan antara variabel Latar belakang pendidikan $\left(\mathrm{X}_{1}\right)$, pengalaman $\left(\mathrm{X}_{2}\right)$ dan kompetensi teknik $\left(\mathrm{X}_{3}\right)$ terhadap kinerja auditor (Y) pada Inspektorat Kab. Lamongan. Hasil analisis diperoleh $F_{\text {Hitung }}$ sebesar 22,022, sedangkan pada taraf signifikan $\alpha=$ 0,05 nilai $\mathrm{F}_{\text {Tabel }}$ sebesar 3,24 dengan Probabilitas (Sig.) sebesar 0,000 lebih kecil dari 0,05, maka diperoleh asumsi bahwa $\mathrm{H}_{0}$ ditolak dan $\mathrm{H}_{\mathrm{a}}$ diterima, sehingga teruji bahwa secara bersamasama terdapat pengaruh yang signifikan antara latar belakang pendidikan $\left(\mathrm{X}_{1}\right)$, pengalaman $\left(\mathrm{X}_{2}\right)$ dan kompeteni teknik $\left(\mathrm{X}_{3}\right)$ terhadap Kinerja auditor (Y).

\section{KESIMPULAN DAN SARAN Keimpulan}

Dari hasil uji secara simultan di peroleh nilai $\mathrm{F}_{\text {hitung }}=22,022>\mathrm{F}_{\text {Tabel }}=$ 3,24, yang berarti bahwa Latar belakang Pendidikan $\left(\mathrm{X}_{1}\right)$, Pengalaman $\left(\mathrm{X}_{2}\right)$ dan Kompetensi teknik $\left(\mathrm{X}_{3}\right)$, mempunyai pengaruh yang signifikan secara simultan terhadap kinerja Auditor pada Inspektorat Kab. Lamongan.

Berdasarkan analisis korelasi parsial yaitu Latar belakang Pendidikan $\left(\mathrm{r}_{1}\right)=0,739$, Pengalaman $\left(\mathrm{r}_{2}\right)=0,801$, Kompetensi teknik $\left(\mathrm{r}_{3}\right)=$ 0,779 , yang artinya mempunyai hubungan yang kuat terhadap Kinerja auditor (Y) pada Inspektorat kab. Lamongan. Sehingga $\mathrm{H}_{0}$ ditolak dan $\mathrm{H}_{\mathrm{a}}$ diterima, yang artinya variabel Latar belakang pendidikan $\left(\mathrm{r}_{1}\right)$, Pengalaman $\left(r_{2}\right)$ dan Kompetensi teknik $\left(\mathrm{r}_{3}\right)$ mempunyai pengaruh yang signifikan secara parsial terhadap kinerja pegawai auditor (Y) pada Inspektorat Kab. Lamongan.

Dari melihat hasil regersi berganda

$\mathrm{Y}=1,786+0,467 \mathrm{X}_{1}+0,672 \mathrm{X}_{2}+0,384 \mathrm{X}_{3}$ dan nilai Korelasi Latar belakang pendidikan $\left(r_{1}\right)=0,736$, Pengalaman $\left(\mathrm{r}_{2}\right)=0,801$, Kompetensi teknik $\left(\mathrm{r}_{3}\right)=$ 0,779, maka dapat dibuktikan bahwa variabel Pengalaman mempunyai pengaruh paling dominan terhadap kinerja auditor pada Inspektorat Kab. Lamongan yang diperoleh dengan nilai $\mathrm{X}_{2}=0,672$ dan $\mathrm{r}_{2}=0,801$.

\section{Saran}

Adapun saran dari penulis dari hasil penelitian yang sudah dilakukan oleh penulis pada Inspektorat Kab. Lamongan :

Bagi auditor:

Secara umum Kinerja Auditor dipengaruhi oleh beberapa faktor. Dalam penelitihan ini dipengaruhi oleh faktor Latar Belakang Pendidikan, Pengalaman, dan Kompetensi Teknik untuk meningkatkan Kinerja Auditor dibutuhkan Pendidikan yang diperoleh dari bangku perkuliahan maupun pelatihan. Begitu juga bagi auditor junior dengan model pendamping akan dapat mendapat pengalaman, sehingga dalam kurun waktu tertentu dapat melaksanakan pekerjaan yang diembanya dengan baik. Sedangkan bagi auditor yang sudah senior harus terus memperbanyak pelatihan seperti diklat substansi, melaksanakan audit secara rutin dan melakukan simulasi 
akan meningkat an keterampilan

dalam melaksanakan tugas yang diembanya dan akan dapat minimalkan kesalahan.

Bagi peneliti lain:

a. Peneliti mendatang sebaiknya melakukan sebuah dengan menggunakan metode wawancara langsung untuk mengumpulkan data penelitihan agar dapat mengurangi adanya kelemahan terkait interval validty

b. Peneliti juga menyarankan untuk penelitihan selanjutnya agar memperluas objek penelitihan pada aparat insepektorat Kab/kota Se-Provinsi jawa timur sehingga hasilnya dapat digeneralisasi.

\section{DAFTAR PUSTAKA}

Badan pemeriksa keuangan, 2007, Peraturan Badan Pemeriksa Keuangan Republik Nomor 01 Tahun 2007 Tentang Standar Pemeriksaan Keuangan Negara

Muh, Taufiq Efendy, 2010 Pengaruh Kompetensi, Indepedensi, Dan Motivasi Terhadap Kualitas Audit Aparat Inspektorat Dalam Pengawasan Keuangan Daerah (Studi Empiris Pemerintah Gorontalo ), Tesis Program Studi Magister Sains Program Pasca Sarjana Universitas Diponegoro.

Putri, 2009, Pelatihan Indepedensi Terhadap Presepsi Tentang Kualitas Oleh Auditor Yang Berkerja Pada Kantor Akutan Publik (KAP) di Jakarta Barat,
Jakarta: Tesis Universitas Bina Nusantara.

Rena Mareta, 2011, Pengaruh Tingkat Pendidikan, Pengalaman Dan Kompensasi Terhadap Kinerja Auditor Pada Kantor Akutan Publik di Daerah Istimewah Yogyakarta, Semarang Skripsi Fakultas Ekonomi Universitas Negeri Yogyakarta.

Siti Nur Mawar, 2010, pengaruh kompetensi dan indepedensi auditor terhadap kualitas Adudit (Studi kasus pada auditor KAP Di semarang). Semarang: Universitas diponegoro. 